\title{
POTENSI PLTMH PADA FASILITAS BPT MILIK PDAM - SUATU STUDI KASUS DI PDAM KABUPATEN WONOGIRI
}

\author{
Wahyu Budi Mursanto \\ Jurusan Teknik Konversi Energi, Politeknik Negeri Bandung \\ email :wahyupoli@yahoo.com
}

\begin{abstract}
Abstrak
Sumber air mimum untuk suatu kota atau daerah, banyak yang berasal dari sumber air yang berada di pegumungan. Dikarenakan letaknya yang cukup tinggi, untuk mengalirkan air tersebut pihak PDAM menggunakan pipa-pipa tertutup secara gravitasi. Jika jarak pengalirannya cukup jauh, maka pipa-pipa tersebut dilengkapi dengan Bak Pelepas Tekanan (BPT). Fungsi dari BPT adalah melepaskan energi air yang ada di pipa bertekanan agar tidak merusak/memecahkan pipa. Pada penelitian ini akan dihitung potensi energi air yang ada pada suatu BPT untuk dimanfaatkan sebagai PLTMH. Sebagai studi kasus dipilih salah satu BPT milik PDAM Kabupaten Wonogiri Jawa Tengah yang mempunyai fasilitas pompa sumur dalam yang digerakkan dengan motor listrik $(14,92 \mathrm{~kW})$ yang energi listriknya berasal dari genset Diesel $(23 ; 87 \mathrm{~kW})$. Air dari sumur dalam tersebut digunakan untuk menambah pasokan air mimum pada saat musim kemarau. Hasil penelitian memperlihatkan bahwa ditemukan solusi untuk menggantikan mesin genset Diesel dengan PLTMH yang menggunakan turbin Pelton maupun crossflow. Pemilihan penggunaan turbin crossflow untuk penelitian ini, karena turbin ini mampu mememuhi spesifikasi yang dinginkan, harganya lebih murah serta diproduksi secara lokal di Indonesia.
\end{abstract}

Kata kunci : Bak Pelepas Tekan, PLTMH, turbin pelton, turbin crossflow

\section{PENDAHULUAN}

Bila ditinjau dari sudut pandang keenergian, setiap saat, energi potensial yang ada pada segmen antar jaringan perpipaan di satu BPT (Bak Pelepas Tekanan) dengan BPT berikutnya terbuang secara percuma. Sebenarnya energi potensial air ini dapat dimanfaatkan untuk memutar turbin air untuk kemudian dikonversikan menjadi bentuk energi lain, khususnya energi listrik. Besarnya energi listrik yang dihasilkan tentunya akan bergantung pada debit air dan head efektif yang mengalir di pipa transmisi tersebut. Artinya, ada suatu potensi untuk membangkitkan listrik tenaga air skala kecil (PLTMH) pada tiap bangunan BPT ini.

Jika PLTMH tersebut dapat direalisasikan, maka energi listrik yang dihasilkan akan dapat digunakan untuk berbagai keperluan bagi kepentingan PDAM sendiri. Sebagai contoh: di Kabupaten Wonogiri ketika musim kemarau mereka kekurangan air; sumber dari mata air yang ada tidak memenuhi kebutuhan, sehingga pihak PDAM membuat sumur dalam di dekat BPT untuk menambah pasokan air. Seandainya ada potensi PLTMH pada BPT tersebut, maka dapat dibuat instalasi PLTMH yang dapat menghasilkan listrik. Energi listrik yang dihasilkan dapat digunakan untuk memompa air dari sumur dalam yang berada di lokasi BPT tersebut. Dengan demikian pihak PDAM tidak perlu membayar listrik atau solar untuk genset dalam rangka memenuhi kebutuhan listrik untuk pompanya.

\section{KONDISI UMUM BPT DI KABUPATEN WONOGIRI}

PDAM Wonogiri mengelola sumber air dari berbagai daerah untuk mencukupi kebutuhan masyarakat. Khusus untuk Kecamatan Kota Wonogiri, air untuk kebutuhan masyarakat dipenuhi dari lereng pegunungan Lawu di Kecamatan Jatinom Kabupaten Karanganyar. Instalasi pembawa air tersebut adalah pipa yang berdiameter $250 \mathrm{~mm}$ yang disambung sampai puluhan kilometer. Perbedaan tinggi elevasi dataran dari sumber air di Desa Kurya Kecamatan Jatinom sampai Kecamatan Wonogiri mencapai 
ratusan meter. Kondisi ini membuat PDAM membuat BPT di setiap interval antara 70 sampai 100 meter perbedaan elevasi. Dengan demikian, adanya potensi debit dan head merupakan sumber energi yang dapat dimanfaatkan untuk keperluan PDAM sendiri.

PDAM Wonogiri mengelola mata air, yang tersebar di seluruh wilayah Kabupaten Wonogiri. Mata air yang diambil terdiri dari sumber mata air murni yang muncul ke permukaan bumi, maupun mata air yang berasal dari sumur dalam. Mata air dan sumur dalam, serta instalasi penjernihan air dapat disebutkan sebagai berikut:

1. Mata air desa Kurya Kecamatan Jatiyoso Kabupaten Karanganyar

2. Mata air Tempel Wuryantoro

3. Mata air Banyu Anjog

4. Sumur Dalam Mongsari Girimarto, yang hanya beroperasi pada waktu musim kemarau saja.

5. Sumur Dalam Ngadirojo

6. Mata Air Genukharjo Wuryantoro

7. Mata Air Bakalan Purwantoro

8. Mata Air Supit Urang Jatisrono

9. Mata Air Silamuk Slogohimo

10. Mata Air Nangsri Pracimantoro

11. Mata Air Umbul Nogo Manyaran

12. Mata Air Semawur Baturetno

13. Mata Air Luweng Sapi Giritontro

14. Mata Air Sumur Gedhe Batiwarno

15. Mata Air Bendung Malang Girimarto Sidoharjo

16. Mata Air Kakao Giriwoyo

17. Mata Air Sumber Eromoko

18. Mata Air Waru Paranggupito

Dalam pengoparasiannya, sumber air di atas kebanyakan menggunakan gaya gravitasi untuk menyalurkan ke rumah penduduk. Hanya beberapa tempat seperti di Giritontro, Pracimantoro dan Giriwoyo yang menggunakan mesin pendorong untuk menaikkan air menuju bak penampungan untuk didistribuskan ke rumah-rumah.
Pada instalasi PDAM di Desa Kurya Kecamatan Jatiyoso Kab Karanganyar yang merupakan salah satu sumber mata air yang menyuplai air minum di Kecamatan Kota Wonogiri, air mengalir secara gravitasi dari desa Kurya yang mempunyai ketinggian $1100 \mathrm{dpl}$ dan dialirkan ke Kota Kecamatan Giritirto Wonogiri dengan ketinggian 156 dpl. Jika dilihat selisih ketinggiannya, maka terdapat selisih ketinggian sebesar 1100 $156=944$ meter. Jika pipa yang digunakan tidak dilakukan pemutusan dalam bentuk BPT-BPT, maka tekanan air terhadap pipa menjadi sangat besar dan tidak mungkin pipa PDAM akan bertahan.

Instalasi PDAM dari desa Kurya menuju ke Kecamatan Kota Giritirto Wonogiri terdapat 6 BPT, 1 Reservoir dan 1 Bak Filtrasi yang berfungsi sebagai tempat untuk membuang tekanan air sehingga menjadi sama dengan tekanan udara luar.

\section{POTENSI UMUM}

Telah dilakukan penelitian untuk potensi pembangkitan energi listrik untuk jaringan pipa yang berasal dari mata air di desa Kurya Kecamatan Jatiyoso Kab. Karanganyar.

Potensi daya listrik terutama dihitung untuk data debit minimum pada musim kemarau, namun tidak menutup kemungkinan memanfaatkan debit pada musim penghujan sehingga diperoleh daya yang cukup besar. Persoalannya adalah pada jenis turbin yang akan digunakan karena akan berpengaruh pada efisiensi dan jumlah debit minimum yang masih bisa digunakan agar turbin tetap aman beroperasi. Sementara itu, untuk memilih turbin yang akan digunakan bergantung pada jumlah debit rencana dan head efektif. Dengan demikian pemilihan turbin yang akan digunakan tergantung pada basic design dari keinginan pemakai.

Sebagai basic design pada penelitian ini adalah memanfaatkan PLTMH untuk memompa air sumur pada musim kemarau 
dan kelebihan daya (terutama pada musim penghujan) dapat digunakan untuk kepentingan lain.

Di lokasi dimana BPT-1 berada, sudah ada sumur dalam dan instalasi pompa yang digunakan sebagai tambahan pasokan air pada saat musim kemarau. Instalasi ini berada di BPT-1 di dusun Mongsari. Kekuatan motor listrik pompa sebesar $20 \mathrm{hp}$ dengan penggerak berupa generator set dengan kekuatan 32 hp. Genset menggunakan bahan bakar solar. Pada musim kemarau mesin ini dijalankan selama 5 jam setiap harinya.
Berdasarkan kondisi tersebut, maka perlu dihitung potensi PLTMH apakah bisa memenuhi kebutuhan yang diinginkan atau tidak. Perlu dihitung potensi pada musim kemarau, dimana air berada pada kondisi minimum dan dihitung potensi pada musim penghujan, dimana air berlebih. Dengan demikian akan diperoleh gambaran mengenai potensi PLTMH di BPT yang ada. Selanjutnya potensi PLTMH dapat digunakan untuk menggantikan genset yang telah terpasang, maupun jika ada kelebihan pasokan dapat digunakan untuk keperluan lainnya. Berikut pada Tabel-1 adalah data potensi untuk tiap BPT yang diteliti.

Tabel-1 Data Potensi BPT

\begin{tabular}{|l|c|c|c|c|c|c|c|}
\hline Skema & 1 & 2 & 3 & 4 & 5 & 6 & 7 \\
\hline Nama instalasi di hulu & BPT 6 & BPT 1 & $\begin{array}{c}\text { Bak } \\
\text { Filtrasi }\end{array}$ & BPT 2 & BPT 3 & BPT 4 & BPT 5 \\
\hline Nama daerah di hulu & Selobentar & Selobentar & Mongsari & Koripan & Jagir & Jatirejo & Bulu \\
\hline Elevasi di hulu (m) & 873 & 799 & 674 & 583 & 513 & 436 & 364 \\
\hline Nama instalasi di hilir & BPT 1 & $\begin{array}{c}\text { Bak } \\
\text { Filtrasi }\end{array}$ & BPT 2 & BPT 3 & BPT 4 & BPT 5 & Reservoir \\
\hline Nama daerah di hilir & Selobentar & Mongsari & Koripan & Jagir & Jatirejo & Bulu & Bakalan \\
\hline Elevasi di hilir $(m)$ & 799 & 674 & 583 & 513 & 436 & 364 & 290 \\
\hline Head $(m)$ & 74 & 125 & 91 & 70 & 77 & 72 & 74 \\
\hline Panjang lintasan pipa $(m)$ & 1350 & 2141.5 & 2443 & 1666 & 1858.5 & 2287.5 & 2708 \\
\hline Diameter pipa $(m)$ & 0.25 & 0.25 & 0.25 & 0.25 & 0.25 & 0.25 & 0.25 \\
\hline Debit minimum rata-rata $\left(\mathrm{m}^{3} / \mathrm{s}\right)$ & 0.03 & 0.03 & 0.03 & 0.03 & 0.03 & 0.03 & 0.03 \\
\hline Debit maximum rata-rata $\left(\mathrm{m}^{3} / \mathrm{s}\right)$ & 0.12 & 0.12 & 0.12 & 0.12 & 0.12 & 0.12 & 0.12 \\
\hline
\end{tabular}

\section{PERHITUNGAN POTENSI PLTMH}

Perhitungan head efektif dapat dicari dengan menghitung selisih head bruto dikurangi dengan head losses pada pipa. Head losses dapat disebabkan oleh adanya major losses dan minor losses. Major losses diakibatkan adanya gesekan pada pipa, sedangkan minor losses adalah rugi-rugi energi yang diakibatkan adanya belokan pipa, entrance, reducer, expansion, dll. Pada perhitungan head efektif yang dilakukan, hanya memperhitungkan head loss akibat major losses saja. Kehilangan head akibat minor losses akan diperhitungkan sesuai dengan kondisi skema yang ada.
Pertama dihitung kecepatan aliran air. Kecepatan air dapat dihitung dari data debit dan diameter pipa. Sebagai contoh pada perhitungan ini digunakan data debit pada musim kemarau.

$Q=v A \ldots \ldots \ldots \ldots \ldots \ldots$

Atau: $v=\frac{Q}{A}=\frac{Q}{\frac{1}{4} \pi D^{2}}$

Data yang diperoleh adalah $\mathrm{Q}=30$ liter $/$ detik $=0,030 \mathrm{~m}^{3} / \mathrm{s}$, dan $\mathrm{D}=250$ $\mathrm{mm}=0,25 \mathrm{~m}$, sehingga didapat: 


$$
v=\frac{0,030}{\frac{1}{4} \pi(0,25)^{2}}=0,61 \mathrm{~m} / \mathrm{s}
$$

Kooefisien gesek $\mathrm{f}$ dapat dihitung dengan menggunakan bantuan grafik Moody (Moody chart) maupun dengan iterasi berdasarkan formula Blasius dan Colebrook. Pada perhitungan yang dibuat ini, dipilih cara yang kedua, yaitu dengan menggunakan iterasi ${ }^{[1]}$.

Pertama dihitung relative roughness (kekasaran relatif), $\varepsilon / \mathrm{D}$. Nilai ini langsung dicari melalui tabel kekasaran relatif jika diketahui diameter pipa dan jenis pipa yang digunakan. Pada kasus ini, jenis pipa yang digunakan adalah pipa jenis $\mathrm{Ci}$, yaitu jenis pipa baja komersial. Dari tabel kekasaran diperoleh dengan nilai $\varepsilon / \mathrm{D}=0,000184$.

Kemudian dihitung nilai bilangan Reynold, Re; dimana,

$\operatorname{Re}=\frac{4 Q}{\pi v D}$

Dengan $v$ adalah viskositas kinematik yang nilainya juga bergantung pada temperatur. Pada kondisi ini temperatur air dianggap sebesar $20^{\circ} \mathrm{C}$, sehingga dari tabel sifat-sifat air diperoleh nilai viskositas kinematik sebesar $1 \times 10^{-6} \mathrm{~m}^{2} / \mathrm{s}$.

Dengan demikian nilai Re adalah

$$
\begin{aligned}
& \operatorname{Re}=\frac{4(1,16)}{\pi\left(1.0 \times 10^{-6}\right)(0,25)}=662139.74 \\
& \text { (turbulen) }
\end{aligned}
$$

Karena aliran adalah turbulen maka rumus Blasius digunakan untuk menebak nilai koefisien gesek $f$ sesuai dengan persamaan 3:

$$
f=\frac{0,3164}{\operatorname{Re}^{0,25}}
$$

Nilai f pertama adalah $:=0,0157$
Kemudian digunakan rumus Colebrook untuk menghitung $f_{\text {new }}$ (persamaan 4):

$$
\begin{aligned}
& f_{\text {new }}=\frac{0,25}{\left[\log \left(\frac{\varepsilon / D}{3,7}+\frac{2,51}{\operatorname{Re} \sqrt{f_{\text {old }}}}\right)\right]_{\ldots}^{2}} \\
& f_{\text {new }}=\frac{0,25}{\left[\log \left(\frac{0,00018}{3,7}+\frac{2,51}{290298,61 \sqrt{0,0157}}\right)\right]^{2}} \\
& f_{\text {new }}=0.01360226,
\end{aligned}
$$

Nilai ini kemudian dimasukkan sebagai nilai $\mathrm{f}_{\text {old }}$ pada rumus Colebrook, untuk memperoleh nilai $f$ yang baru. Iterasi dilakukan sampai diperoleh nilai $f$ yang konvergen.

Nilai $f_{\text {new }}$ berikutnya adalah

$$
f_{\text {new }}=0.013595284
$$

Nilai $\mathrm{f}_{\text {new }}$ tersebut kemudian diiterasi lagi dan menghasilkan nilai,

$$
f_{\text {new }}=0.01359526
$$

Diiterasi lagi, dan diperoleh

$$
f_{\text {new }}=0.013595259
$$

Sampai di sini nilai $f_{\text {new }}$ sudah konvergen. Jadi diperoleh nilai koefisien gesek, $f=$ 0.013595259

Nilai ini diperoleh untuk pipa baja yang baru, karena pipa yang ada sudah lama digunakan maka koefisien gesek menjadi bertambah besar. Dalam hal ini diasumsikan bahwa nilai gesek yang digunakan dalam perhitungan sebesar 0,02 .

Dengan menggunakan rumus DarcyWeisbach head loss akibat gesekan dapat diperoleh persamaan 5 sebagai berikut: 
$h_{L}=f\left(\frac{L}{D}\right)\left(\frac{v^{2}}{2 g}\right)$

$h_{L}=0,02\left(\frac{2141.5}{0,25}\right)\left(\frac{0,61^{2}}{2(9,81)}\right)$

$h_{L}=3,26$ meter

Rumus untuk kehilangan tinggi tekan akibat minor losses ditunjukkan pada persamaan 6 sebagai berikut :

$h_{b}=K \frac{V^{2}}{2 g}$

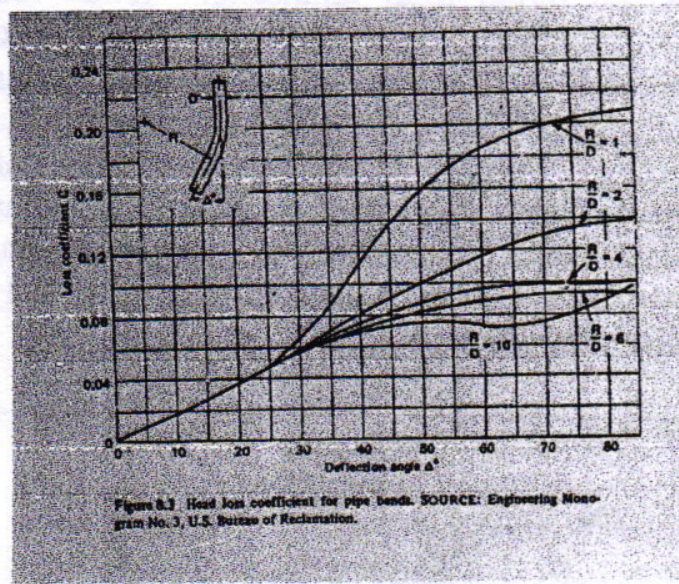

Gambar 1 Koefisen belokan pipa

Dengan $\mathrm{K}$ adalah konstanta yang bergantung pada jenis halangan (obstacle) seperti belokan, penyempitan, katup, dll.
Sebagai gambaran berapa nilai $\mathrm{K}$ untuk belokan dapat dilihat pada gambar 1 berikut ini. Tampak bahwa nilai koefisien $\mathrm{K}$ untuk belokan $20^{\circ}$ berkisar pada harga 0.04 . Makin besar sudut belok nilai $\mathrm{K}$ semakin besar.

Pada kenyataannya, walaupun jalur distribusi air yang melalui pipa bisa mencapai $1-2 \mathrm{~km}$, namun sambungan pipa yang ada didominasi sambungan dengan sudut di bawah $20^{\circ}$. Sebagai contoh dilakukan perhitungan untuk belokan dengan sudut $22^{\circ}$ untuk jalur pipa PDAM. Kecepatan aliran di dalam pipa untuk debit 30 liter/s dengan diameter pipa $250 \mathrm{~mm}$, diperoleh nilai $\mathrm{V}=0,6 \mathrm{~m} / \mathrm{s}$. Sehingga untuk pipa dengan sudut belokan sebesar $22^{\circ}$ akan menghasilkan nilai kehilangan energi tekan sebesar:

$h_{b}=K \frac{V^{2}}{2 g}=0.04 \frac{0,6^{2}}{2 \times 9,81}=0,00073 \mathrm{~m}$

Artinya secara total kontribusi kehilangan energi tekan akibat belokan menjadi relatif kecil. Selain belokan, minor losses juga diakibatkan karena bentuk masukan (entrance), katup (gate valve), expansion dan reduction pipa. Tabel 2 memperlihatkan hasil perhitungan head losses untuk kondisi debit minimum dan maksimum.

Tabel-2 Perhitungan head efektif

\begin{tabular}{|c|c|c|c|c|c|c|c|}
\hline Skema & 1 & 2 & 3 & 4 & 5 & 6 & 7 \\
\hline $\mathrm{V} \cdot$ Disain pada $\mathrm{Q}$ minimum $(\mathrm{m} / \mathrm{s})$ & 0,61 & 0,61 & 0,61 & 0,61 & 0,61 & 0,61 & 0,61 \\
\hline V Disain pada $Q$ maximum $(\mathrm{m} / \mathrm{s})$ & 2,44 & 2,44 & 2,44 & 2,44 & 2,44 & 2,44 & 2,44 \\
\hline Minimum $\rightarrow$ f gesek & 0,0200 & 0,0200 & 0,0200 & 0,0200 & 0,0200 & 0,0200 & 0,0200 \\
\hline Head loss mayor/gesek (m) & 2,06 & 3,26 & 3,72 & 2,54 & 2,83 & 3,48 & 4,12 \\
\hline Head loss minor (m) & 0,08 & 0,09 & 0,09 & 0,08 & 0,08 & 0,09 & 0,09 \\
\hline Head efektif (m) & 69,86 & 119,65 & 85,19 & 65,38 & 72,09 & 66,43 & 67,79 \\
\hline Maximum $\ldots$ f gesek & 0,0200 & 0,0200 & 0,0200 & 0,0200 & 0,0200 & 0,0200 & 0,0200 \\
\hline Head loss mayor/gesek (m) & 32,90 & 52,18 & 59,53 & 40,60 & 45,29 & 55,74 & 65,99 \\
\hline Head loss minor (m) & 1,29 & 0,72 & 0,75 & 0,67 & 0,69 & 0,73 & 0,78 \\
\hline Head efektif (m) & 37,82 & 70,10 & 28,72 & 26,73 & 29,02 & 13,52 & 5,23 \\
\hline
\end{tabular}


Tampak bahwa pada kondisi debit minimum, kecepatan air juga menjadi kecil; sehingga berakibat pada head losses total yang kecil. Dengan demikian, head efektif tidak banyak berkurang. Sebagai contoh untuk BPT-1 (skema 2) pada Tabel 2, diperoleh nilai head gross 125 $\mathrm{m}$ yang menghasilkan nilai head efektif sebesar $119,65 \mathrm{~m}$ untuk debit minimum $30 \mathrm{l} / \mathrm{s}$. Pada debit yang maksimum, yaitu sebesar $120 \mathrm{~V} / \mathrm{s}$, head efektifnya menjadi hanya $70,10 \mathrm{~m}$. Jelas bahwa pada kondisi debit maksimum, kecepatan air menjadi lebih besar, sehingga kehilangan tinggi tekan akibat gesekan menjadi lebih besar. Kondisi ini terjadi karena gesekan sebanding dengan kuadrat kecepatan, hal ini berarti semakin tinggi kecepatan maka akan semakin besar gesekan yang terjadi.

\section{ANALISIS PERHITUNGAN POTENSI DAYA PLTMH}

Analisis perhitungan daya PLTMH pada penelitian ini hanya difokuskan pada skema 2 saja. Hal ini dikarenakan pada skema 2 (BPT-1) sudah ada genset berbahan bakar solar yang digunakan sebagai sumber penggerak motor pompa submersible, yang merupakan pompa yang hanya diaktifkan pada musim kemarau dimana pasokan PDAM yang berasal dari mata air mulai berkurang. Daya genset eksisting sebesar $32 \mathrm{Hp}(23,87 \mathrm{~kW})$ dan daya motor pompa sebesar $20 \mathrm{Hp}(14,92 \mathrm{~kW})$.

Dalam penelitian ini, daya elektrik yang dihasilkan oleh PLTMH harus sama atau lebih besar dari daya genset eksisting agar dapat menggerakkan motor pompa submersible. Diasumsikan bahwa daya sebesar $23,87 \mathrm{~kW}$ merupakan daya minimal yang diperlukan untuk menggerakkan motor listrik pompa submersible. Walaupun daya motor pompa lebih kecil, namun karena ada persoalan starting motor, pada saat awal dubutuhkan daya yang lebih besar. Hal ini dilakukan, karena peranan PLTMH nantinya adalah untuk menggantikan genset Diesel yang ada. Namun dalam analisis ini tidak menutup kemungkinan daya yang dihasilkan bisa dimanfaatkan untuk hal yang lain jika memungkinkan.
Pemikiran ini didasari bahwa kalau debit disain dirancang hanya untuk debit minimum, maka pada waktu musim penghujan dimana air berlebih, maka kelebihan air tersebut tidak dapat dimanfaatkan.

Berdasarkan pada Tabel-2, untuk skema 2 saja, maka tampak bahwa variasi debit antara 30 sampai $120 \mathrm{l} / \mathrm{s}$ dengan variasi head efektif antara 70,10 sampai $119,65 \mathrm{~m}$. Dengan menggunakan bantuan gambar 2, turbin yang memenuhi spesifikasi tersebut adalah turbin Pelton dan crossflow (Banki). Keduanya merupakan jenis turbin impuls.

Persoalan yang ada bergantung pada debit berapa turbin akan dirancang. Kalau hanya menggunakan debit tertentu (kurang dari maksimum), maka pada waktu musim penghujan dimana air berlebih, harus ada saluran dengan bukaan katup tertentu yang akan membuang kelebihan debit. Kesulitannya dengan cara ini adalah perlu pengaturan katup, manakala debit total berubah. Tentu saja hal ini akan menyulitkan operator

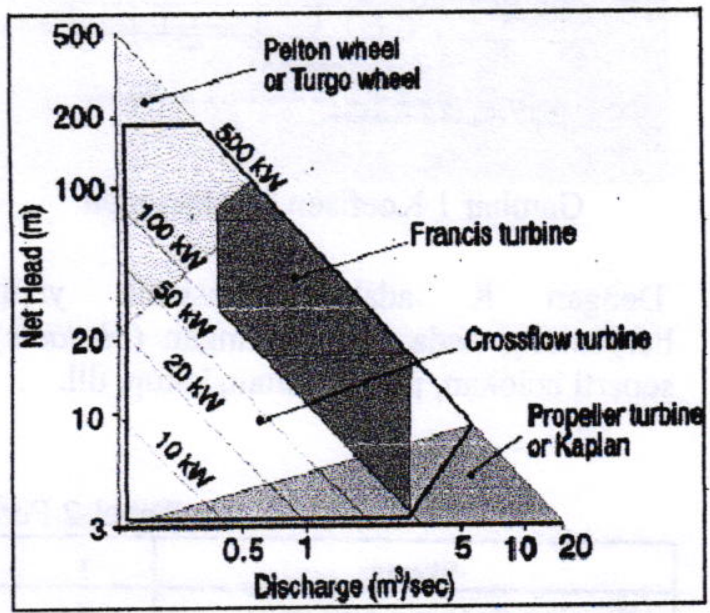

Gambar 2 Grafik pemilihan turbin ${ }^{[2]}$

Jika turbin didisain dengan debit maksimum, persoalannya adalah apakah pada waktu musim kemarau dengan debit minimum; turbin masih bisa beroperasi dengan menghasilkan daya yang mencukupi untuk menggerakkan pompa listrik? Untuk itu harus dianalisis lebih jauh 
kemungkinan yang ada sehingga kriteria tersebut dapat dicapai.

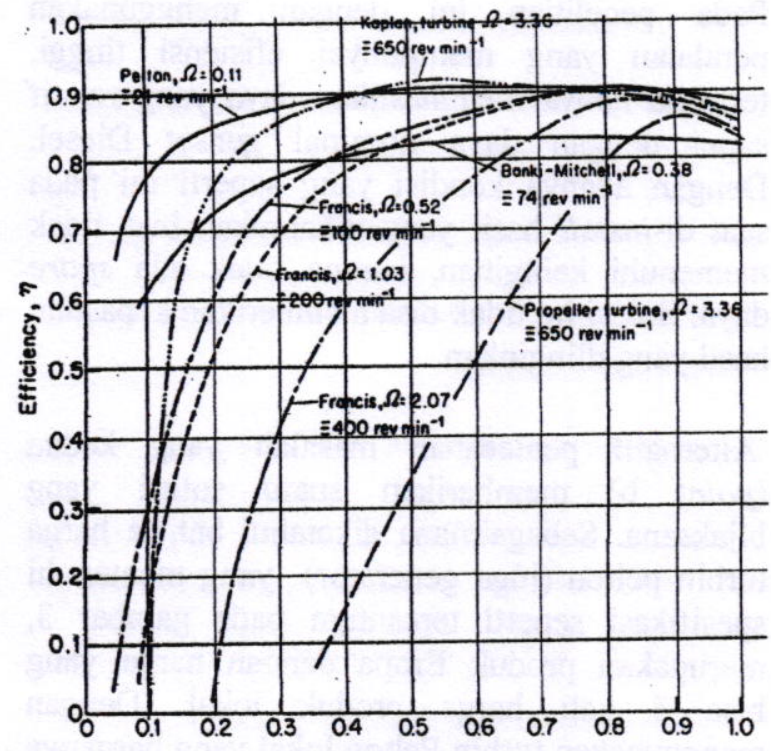

Gambar 3 Efisiensi turbin versus debit ${ }^{[3]}$.

Pertama-tama adalah dengan menentukan jenis turbin yang akan dipakai. Berdasarkan Gambar 3, tampak bahwa turbin Pelton dan crossflow mempunyai efisiensi yang lebih stabil (hampir rata) dibandingkan dengan jenis turbin yang lainnya. Efisiensi turbin Pelton secara keseluruhan lebih bagus daripada turbin crossflow.

Secara umum kedua turbin tersebut masih mempunyai efisiensi yang relatif stabil sampai 0,4 debit maksimum (pada penelitian ini setara dengan debit minimum, 30 1/s). Dikarenakan efisiensi turbin Pelton lebih bagus daripada crossflow, maka akan diuji terlebih dahulu apakah turbin pelton mampu untuk menggantikan genset Diesel. Pada waktu debit berubah, sebenarnya generator juga mempunyai perilaku yang hampir mirip dengan turbin. Artinya dengan berubahnya debit, maka efisiensi generator juga akan berubah.

Tabel 3 berikut ini memperlihatkan hasil perhitungan untuk daya minimum dan maksimum berdasarkan turbin yang dirancang dengan debit disain sebesar $120 \mathrm{l} / \mathrm{s}$. Pada kondisi debit minimum adalah sebesar $30 \mathrm{l} / \mathrm{s}$ atau setara dengan debit 0,4 debit maksimum.

Tabel 3 Hasil perhitungan daya turbin Pelton

\begin{tabular}{|l|r|l|}
\hline \multicolumn{3}{|c|}{ SKEMA-2 (untuk turbin Pelton) } \\
\hline Qmax & 0,12 & $\mathrm{~m} 3 / \mathrm{s}$ \\
\hline H efektif max & 70,10 & $\mathrm{M}$ \\
\hline Q min & 0,03 & $\mathrm{~m} 3 / \mathrm{s}$ \\
\hline H efektif min & 119,65 & $\mathrm{~m}$ \\
\hline Efisiensi turbin max & 0,89 & \\
\hline Efisiensi turbin min & 0,9 & \\
\hline Efisiensi generator max & 0,85 & \\
\hline Efisiensi generator min & 0,8 & \\
\hline Efisiensi transmisi & 0,95 & \\
\hline Daya PLTMH max & 59,30 & $\mathrm{~kW}$ \\
\hline Daya PLTMH min & 22,23 & $\mathrm{~kW}$ \\
\hline
\end{tabular}

Tampak bahwa pada kondisi minimum, daya yang dihasilkan hanya $22,23 \mathrm{~kW}$, sementara untuk menggerakkan motor pompa (karena ada persoalan start awal) harus menggunakan daya minimal sebesar $23,87 \mathrm{~kW}$. Artinya adalah bahwa daya PLTMH yang dihasilkan pada kondisi minimum di musim kemarau tidak bisa digunakan untuk menggerakkan motor listrik untuk pompa.

Secara grafis tampak bahwa efisiensi turbin crossflow lebih rendah dari pada turbin Pelton. Dengan demikian untuk kondisi disain yang sama, pada kondisi musim kemarau ; jika digunakan turbin crossflow akan menghasilkan daya yang lebih kecil daripada turbin Pelton. Dengan demikian jelas bahwa turbin crossflow juga tidak dapat digunakan untuk skema-2 ini.

\section{ALTERNATIF SOLUSI}

Berikut ini beberapa solusi yang memungkinkan agar persoalan tersebut dapat diatasi.

a. Grafik yang ada pada Gambar 3 diambil dari literatur yang mengacu pada produk turbin yang dibuat oleh pabrikan dengan standard yang tinggi (produk Eropa Barat). Dengan demikian perhitungan tersebut sudah dapat dikatakan maksimal perolehannya. 
Dengan memilih produk generator yang mempunyai efisiensi minimal 0,85 pada kondisi 0,4 debit disain; maka akan menghasilkan daya yang dapat digunakan untuk menggerakkan motor pompa. Pada nilai efisiensi generator sebesar 0,85 ini akan dihasilkan daya PLTMH pada kondisi debit minimum sebesar $23,82 \mathrm{~kW}$

b. Dengan membangun wadah yang mampu untuk menampung air dengan kapasitas tertentu di hulu (di BPT-6), sehingga pada saat PLTMH di jalankan pertama kali (start up), daya PLTMH bisa melebihi daya minimal genset. Dengan demikian pada saat start (kondisi transien) dibutuhkan daya yang sama atau lebih besar dari pada daya minimal genset, agar motor listrik pompa dapat dijalankan.

Pada kondisi tunak (steady state), daya yang dibutuhkan untuk menggerakkan pompa sama dengan daya motor listrik nominal $(14,92 \mathrm{~kW})$. Jelas pada kondisi nominal, daya yang dihasilkan oleh PLTMH jauh di atas daya nominal yang dibutuhkan motor.

Jika suatu saat sistem mengalami shut-down, dan harus diperlukan start-up lagi, maka hanya diperlukan waktu beberapa saat untuk melakukan start-up, karena harus menunggu reservoir/wadah yang berada di hulu (di BPT-6) terisi air terlebih dahulu agar PLTMH dapat distart-up dengan daya yang lebih besar. Walaupun pengaliran di pipa pesat berhenti, namun karena BPT-1 juga merupakan tempat penampungan air, maka pengaliran air ke BPT berikutnya tetap tidak terganggu..

\section{PEMILIHAN SOLUSI}

Alternatif solusi yang pertama (point a) memang memberikan suatu pemecahan persoalan. Konsekuensinya adalah kualitas peralatan elektro-mekanik (turbin dan generator) yang bagus akan menghasilkan daya yang diinginkan dan biasanya handal, namun implikasinya adalah biaya peralatan elektromekanik tersebut sangat mahal. Peralatan ini biasanya harus dipesan dari luar negeri.
Persoalan yang mungkin timbul adalah suku cadang yang susah untuk diperoleh.

Pada penelitian ini dengan menggunakan peralatan yang mempunyai efisiensi tinggi, ternyata hanya menghasilkan daya yang relatif sama dengan daya nominal genset Diesel. Dengan adanya kondisi yang seperti ini pada saat di-install hasil yang diharapkan bisa tidak memenuhi keinginan, karena tidak ada spare daya. Solusi ini tidak bisa memberikan kepastian hasil yang diinginkan.

Alternatif pemecahan masalah yang kedua (point b) memberikan suatu solusi yang bijaksana. Sebagaimana diketahui bahwa harga turbin pelton (juga generator) yang memenuhi spesifikasi seperti tercantum pada gambar 3, merupakan produk Eropa dengan harga yang bisa 5 kali harga produk lokal. Dengan menggunakan turbin Pelton lokal yang harganya lebih murah, tentu saja dengan efisiensi yang lebih rendah; bisa diterapkan sistem dengan menggunakan tampungan sementara, dengan demikian akan diperoleh daya yang lebih besar dari pada daya minimal.

Mengingat bahwa harga turbin pelton di pasaran lokal juga masih lebih mahal dibandingkan dengan turbin crossflow untuk skema yang sama, maka ada kemungkinan penggunaan turbin crossflow pada sistem ini bisa dilakukan, walaupun secara efisiensi turbin crossflow juga lebih rendah dari pada turbin Pelton. Turbin crossflow mempunyai keunggulan dalam penyesuaian debit karena dilengkapi dengan pengaturan debit dalam rentang $3 / 3 \mathrm{Q}, 2 / 3 \mathrm{Q}$ dan $1 / 3$ Q; sebagaimana ditunjukkan pada gambar 4.

Dalam penelitian ini turbin crossflow yang dipakai sebagai acuan adalah tipe T-14 yang diproduksi di dalam negeri (Bandung) yang mempunyai karakteristik sebagaimana diperlihatkan pada gambar 5 berikut ini.

Tampak pada Gambar 5, efisiensi turbin crossflow tipe $\mathrm{T}-14$ efisiensinya lebih rendah dibandingkan dengan yang ada pada gambar 3 . 


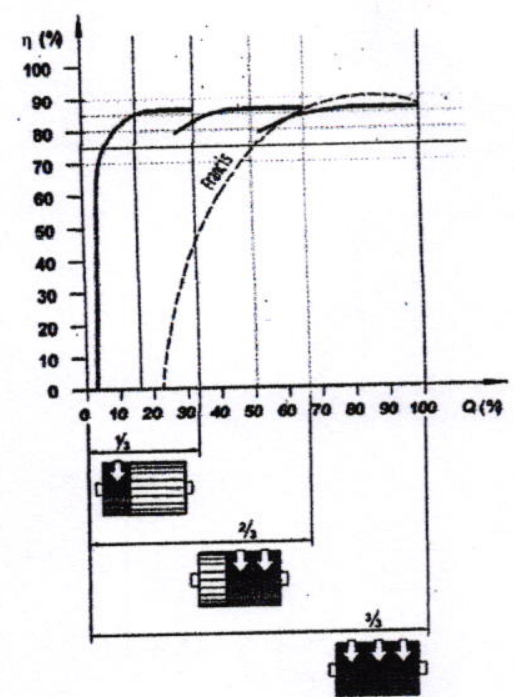

Gambar 4 Pengaturan efisiensi crossflow [4]

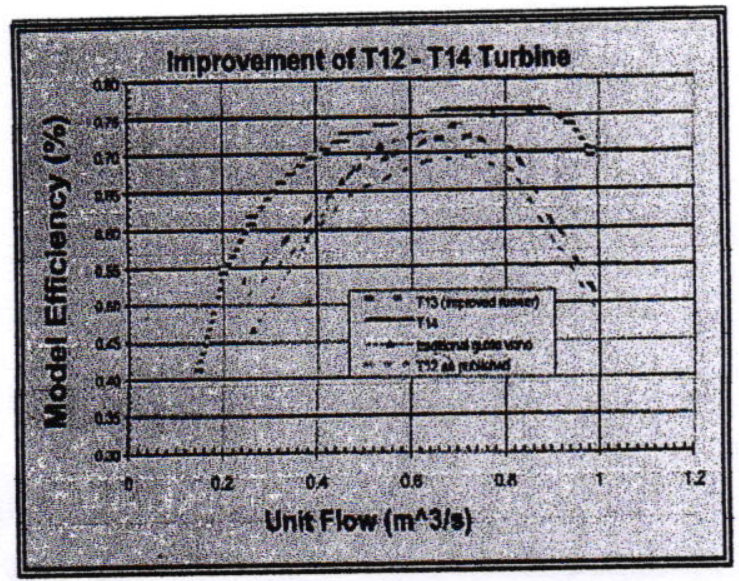

Gambar 5 Efisiensi crossflow tipe T-14 [5]

Tabel 4 Hasil perhitungan turbin crossflow

\begin{tabular}{|l|r|l|}
\hline \multicolumn{3}{|c|}{ SKEMA-2 (turbin crossflow) } \\
\hline Q pada 0,375 Qmax & 0,045 & $\mathrm{~m} 3 / \mathrm{s}$ \\
\hline H efektif max & 115,58 & $\mathrm{M}$ \\
\hline$\eta$ turbin & 0,71 & \\
\hline$\eta$ generator & 0,81 & \\
\hline$\eta$ transmisi mekanik & 0,95 & \\
\hline Daya PLTMH & 26,72 & $\mathrm{~kW}$ \\
\hline
\end{tabular}

Tabel 4 memperlihatkan salah satu hasil perhitungan yang mungkin untuk penggunaan turbin crossflow sesuai dengan alternatif pemecahan masalah pada point b. Hasil perhitungan diperoleh dengan memperhitungkan bahwa waktu yang diperlukan agar air bisa mengisi wadah penampung, agar bisa digunakan untuk start-up diperkirakan selama 10 menit. Selama waktu ini dalam wadah terdapat $18 \mathrm{~m}^{3}$ air. Jika kemudian PLTMH di-start-up dengan debit sebesar $0,045 \mathrm{~m} 3 / \mathrm{s}$ hingga mencapai daya nominalnya (daya $26,72 \mathrm{~kW}$ ), maka daya ini dapat digunakan untuk menjalankan pompa pada saat start-up (transient).

Kondisi transient ini hanya beberapa saat saja, untuk kemudian menjadi tunak (steady state) dengan daya nominal motor pompa $(14,92)$. Maksimum rentang waktu dari saat start-up sampai pompa dapat mengalirkan air dengan kondisi tunak adalah sekitar 6,5 menit. Lebih dari waktu tersebut proses start-up harus diulang dari awal, karena air sudah tidak mencukupi lagi.

Nilai debit, volume penampung, waktu menunggu pengisian dan durasi waktu start-up merupakan variabel yang juga menentukan, tergantung optimasi yang dilakukan. Artinya banyak solusi yang bisa diperoleh dengan cara ini. Hasil perhitungan yang ditunjukkan pada Tabel 4 memperlihatkan salah satu hasil yang mungkin dilakukan. Dalam contoh tersebut dibutuhkan tampungan sebesar $18 \mathrm{~m}^{3}$.

\section{KESIMPULAN}

Solusi dengan memanfaatkan tampungan merupakan suatu pilihan alternatif yang dapat dilakukan. Biasanya instalasi BPT sudah dilengkapi dengan penampung air.

PLTMH dapat menggantikan genset eksisting untuk menyuplai energi listrik bagi motor listrik pompa submersible di Skema-2 (BPT-1) yang ada di PDAM Wonogiri. Keuntungan PLTMH adalah bahwa peralatan bisa bekerja 24 jam dengan biaya produksi listrik secara gratis dan ramah lingkungan; tidak seperti genset Diesel yang membutuhkan bahan bakar solar dan menghasilkan polusi udara dari emisi gas buangnya. 


\section{Daftar Simbol :}

A : luas penampang, $\mathrm{m}^{2}$.

D : Diameter, $\mathrm{m}$.

F : Koefisien gesek.

$\mathrm{H}$ : Head, $\mathrm{m}$.

$\mathrm{P}$ : daya, $\mathrm{kW}$.

Q : debit air, $\mathrm{m}^{3} / \mathrm{s}$.

V : kecepatan aliran air, $\mathrm{m} / \mathrm{s}$.

g : percepatan gravitasi, $\mathrm{m} / \mathrm{s}^{2}$.

$\mathrm{t}$ : waktu, s.

$\eta \quad$ : efisiensi.

$\rho \quad:$ massa jenis air, $\mathrm{kg} / \mathrm{m}^{3}$.

\section{DAFTAR PUSTAKA}

Gerhart P.M., Gross R.J., Fundamentals of Fluid Mechanics, Addison Wesley Publishing Company, Massachusset, 1985.

http://hydropowerstation.com., Hydro Power Electric Plant, Word Press publication,.

Maniton,L., M.Le Nir., J. Roux, Micro Hydroelectric Power Stations, John Wiley \& Sons, 1984, New York.

Harvey A., Brown. A.,Hettiarachi and Inversin A., Microhydro Design Manual : A Guide to small-scale eater power schemes, Intermediate Technology Publications, South hampton, London, 1993.

Cihanjuang Inti Teknik Turbine $\mathrm{T}-14$ Technical Data. 